\title{
Long-term clinical effects of treatment by daytime ambulatory peritoneal dialysis with an individualized dialysis dose mode are comparable to traditional dialysis methods (hemodialysis or continuous ambulatory peritoneal dialysis) for end-stage renal failure
}

\author{
Zhang Zhi-yong, Li Ming-xu, Yu Yong-wu, Zhou Chun-hua \\ Department of Nephrology, Naval General Hospital of PLA, Beijing 100048, China
}

\begin{abstract}
Background: At present, patients with end-stage renal failure (ESRD) face the question of how to achieve adequate dialysis to maintain their survival with the best quality of life as long as possible. Therefore, the choice of suitable dialysis methods and dialysis dose is important.

Objective: To find suitable dialysis methods and an appropriate dialysis dose for patients with ESRD.

Methods: Our research compares the long-term clinical effects between the patients undergoing continuous ambulatory peritoneal dialysis (CAPD), daytime ambulatory peritoneal dialysis (DAPD), and hemodialysis (HD). Thirty-two patients subjected to peritoneal dialysis were selected and divided into group A ( $\mathrm{n}=16)$ and group B $(n=16)$, group A was treated by using the traditional CAPD pattern; group B was treated by using DAPD. Forty-six patients of renal failure at final stage were divided into group A $(n=23)$ and group $B(n=23)$, group A was treated by using a HD method, group B was treated by using a DAPD method.

Results: When the same dialysis dose was applied, the patients with long-term DAPD treatment can obtain satisfactory clinical therapeutic efficacy for the period of maintenance dialysis, thoroughness of dialysis, maintenance of nutritional status, blood pressure regulation, reduction in incidence rate of peritoneal infection, maintenance of relatively high activity in daily life and alleviation in depression, comparable to patients treated with traditional CAPD or HD methods.
\end{abstract}

Conclusion: The long-term clinical effects of DAPD are comparable to CAPD or HD.

Keywords: CAPD, continuous ambulatory peritoneal dialysis, DAPD, daytime ambulatory peritoneal dialysis, end-stage renal failure, hemodialysis

Hemodialysis is a common clinical treatment in ESRD patients. It has the following advantages: effective removal of water and small molecules, rapid relief of emergency complications of uremia such as high concentrations of potassium, acidosis, heart failure, long-term operation, and essential preparation before kidney transplantation. However, because of its limitation in removal of medium-sized molecules, long-term hemodialysis often results in the accumulation of molecules in the body that lead to further symptoms. These include increased body cavity effusion, and secondary amyloidosis among others. Long-term hemodialysis is not suitable for the

Correspondence to: Zhang Zhi-yong, Department of Nephrology, Naval General Hospital of PLA, Beijing 100048, China. E-mail: zhiyongzhang2@163.com patients with conditions including severe hypertension, cardiovascular disease, diabetes, poor condition of blood vessels, and severe bleeding tendency [1].

Peritoneal dialysis (PD) is increasingly becoming the preferred method for dialysis of ESRD patients because it helps protect residual renal function, results in relatively stable hemodynamics, and involves easy operation. However, dialysis programs in different countries and regions are different. Daily $4 \times 2 \mathrm{~L}$ dialysate CAPD programs are currently used in European countries and most parts of China. We need to change the traditional mode of CAPD because of its low efficiency in removal of small molecules, high incidence of malnutrition, high risk of peritoneal infection, and peritoneal ultrafiltration failure after 2-3 years dialysis in patients who undergo CAPD treatment. DAPD may be used for maintenance of 
peritoneal dialysis patients with different dialysis doses according to specific circumstances in order to obtain satisfactory clinical effects.

\section{Material and methods Patients}

The patients in this study were treated in our department from 2000 to 2011 for ESRD. They all clearly had no history of mental illness or physical disabilities. Their primary diseases were glomerulonephritis, diabetic nephropathy, lupus nephritis, chronic pyelonephritis, arteriosclerosis, or interstitial nephritis. The study was approved and registered by the Naval General Hospital of PLA and our institutional ethics committee approved the relating screening, treatment, and data collection from these patients. All subjects signed a written informed consent form. All works were undertaken following the provisions of the Declaration of Helsinki.

\section{Dialysis treatment}

Continuous ambulatory peritoneal dialysis (CAPD)

A double piping dialysis machine (Baxter, Deerfield, IL, USA) was used for peritoneal dialysis. Glucose was the dialysate penetrant. According to the patient's condition, different concentrations of $1.5 \%$, $2.5 \%$, or $4.25 \%$ were used. The dialysis dose was $8 \mathrm{~L}$. Four exchanges were conducted and left in the abdomen at night. CAPD can improve renal failure complications, such as blood pressure adjustment, regulation of acid-base balance and electrolyte disorders.

\section{Daytime ambulatory peritoneal dialysis (DAPD)}

The dialysis machine, dialysate penetrant, and concentrations were the same as for CAPD. A range of 4-8 L dialysis was conducted during the daytime, exchanged 2-4 times every 3-4 h for the dialysis with a dry peritoneal cavity at night. End-stage renal failure complications were treated and symptoms improved.

\section{Hemodialysis (HD)}

The Seldinger technique was used in HD with an area of $1.3-1.5 \mathrm{~m}^{2}$ polysulfone membrane dialyzer. Blood flow 200-350 $\mathrm{ml} / \mathrm{min}$ and dialysate flow $500 \mathrm{ml} / \mathrm{min}$ using standard bicarbonate dialysis as the dialysate penetrant. It was conducted three times a week, and the duration of dialysis was $12-15 \mathrm{~h} / \mathrm{w}$.

\section{Physiological indicators}

Patient's body weight, daily ultrafiltration volume, daily urine volume, blood pressure were monitored and the blood biochemical parameters, peritoneal fluid routine were tested every month. The dialysis sufficiency [2, 3] (Kt/V (week) and Ccr), nutrition status (SGA and sALB), control over complications including hemoglobin ( $\mathrm{Hb}$ ), carbon dioxide combining power $\left(\mathrm{CO}_{2} \mathrm{CP}\right)$, serum potassium $\left(\mathrm{K}^{+}\right)$, serum calcium $\left(\mathrm{Ca}^{2+}\right)$, serum phosphorus $(\mathrm{P}-)$, free parathyroid hormone (iPTH), level of blood pressure controlling status (mean arterial blood pressure, MAP), and abdominal infection rate were monitored and compared.

The daily life ability was evaluated using the Barthel index (BI). The degree of depression was scored using the Hamilton Depression Scale (HAMD).

\section{Statistics}

The experimental data are expressed as means \pm SD. Variance analysis was used for the comparison of the interclass mean values. The mean comparison between the groups was tested by ANOVA, and the comparison between two groups was analyzed using a $t$ test or $\chi^{2}$ test. A $p<0.05$ was considered statistically significant.

\section{Results \\ Long-term clinical effects comparison of CAPD and DAPD treatment}

Thirty-two outpatient or hospitalized patients subjected to peritoneal dialysis in our hospital were selected and then randomized into group $A(n=16)$ or group $B(n=16)$. Group A patients were treated using the standard CAPD treatment, the volume for dialysis per day was $8 \mathrm{~L}$, four exchanges were conducted, and left in the abdomen at night. Group B patients were treated using the DAPD, using a volume of $8 \mathrm{~L}$ and conducted during the daytime for the dialysis with the peritoneal cavity left dry at night. No statistical differences were found between group with respect to age, sex, weight, height, type of disease (percentage of nondiabetic) $(p>0.05)$ (data is not shown).

When patients started their own mode of dialysis, we collected the relevant data and information (Table 1). We evaluated the adequacy of long-term peritoneal dialysis by Kt/V (weeks), and Ccr. We assessed patient nutritional status based on the incidence of malnutrition (SGA), serum albumin level 
(sALB), and observed disease control including the complications of chronic renal failure using a variety of indicators, including $\mathrm{Hb}, \mathrm{CO}_{2} \mathrm{CP}, \mathrm{K}^{+}, \mathrm{Ca}^{2+}$, $\mathrm{P}$-, and iPTH. Assessment of daily living skills was conducted using the BI and depression was evaluated using HAMD scores. The results showed that there are no significant difference $(p>0.05)$ in these index between $\mathrm{A}$ and $\mathrm{B}$ groups.

When the patients were treated continuously for 5 years (60 months), the above relevant data were compared (Table 2). Some patients in Group A were unable to continue treatment by CAPD or DAPD. Such patients were excluded and no longer observed or compared. However, the CAPD treatment time was recorded. Most patients were able to continue treatment by DAPD in group B. There was no significant difference $(p>0.05)$ in residual urine volume, daily dialysis ultrafiltration, dialysis adequacy (Kt/V (weeks), Ccr), or complications controls (level of $\mathrm{CO}_{2} \mathrm{CP}, \mathrm{K}^{+}, \mathrm{Ca}^{2+}$ ) between patients in groups $\mathrm{A}$ and $\mathrm{B}$. Patients in group $\mathrm{B}$ were much better than group A in nutritional status, control of some complications of chronic renal failure such as the level of $\mathrm{Hb}, \mathrm{P}-$, iPTH, mean arterial blood pressure, the rate of abdominal infection, dialysis duration, the employment rate, BI, and HAMD $(p<0.05)$.

\section{Long-term clinical effects comparison of HD and DAPD treatment}

Forty-six outpatient or hospitalized patients with final stage renal failure in our hospital were randomized into group A and group B, 23 patients were included in each group. Group A patients were treated using HD (including conventional HD, hemodiafiltration (HDF), hemoperfusion (HP) and other methods, dialysis was conducted three times a week, and the duration of dialysis was $12-15 \mathrm{~h} / \mathrm{w}$; group B patients were treated using a DAPD method, the volume of consumed dialysate was $6-8 \mathrm{~L}$ per day, the time for exchanging each bag of peritoneal dialysis fluid was 3-4 h, with a dry peritoneal cavity at night. No statistical differences in age, sex, weight, height, type of disease (percentage of nondiabetic) were observed $(p>0.05)$ (data is not shown).

When patients start their own mode of dialysis, the relevant data and information was collected (Table 3). The results showed that there was no significant difference $(p>0.05)$ in the adequacy of long-term peritoneal dialysis; the nutritional status; the disease control situation of complications; BI and HAMD between A and B groups.

Table 1. Clinical effect comparison at the beginning of peritoneal dialysis

\begin{tabular}{|c|c|c|c|c|}
\hline Index & Agroup & B group & $t$ & $p$ \\
\hline Urine volume (ml/d) & $1046 \pm 414$ & $1106 \pm 288$ & 0.481 & 0.634 \\
\hline Ultrafiltration volume (ml/d) & $670 \pm 125$ & $626 \pm 294$ & 0.538 & 0.595 \\
\hline \multicolumn{5}{|l|}{ Adequacy of long-term peritoneal dialysis } \\
\hline Kt/V (week) & $1.54 \pm 0.41$ & $1.32 \pm 0.75$ & 1.010 & 0.321 \\
\hline $\operatorname{Ccr}\left(\mathrm{L}\right.$ week ${ }^{-1} \quad\left(1.73 m^{2}\right)^{-1}$ & $58.62 \pm 8.35$ & $56.23 \pm 10.44$ & 1.181 & 0.247 \\
\hline \multicolumn{5}{|l|}{ Nutritional status } \\
\hline The incidence of malnutrition (SGA) & $13.3 \%$ & $10.5 \%$ & $*$ & 1.000 \\
\hline sALB (g/L) & $37.4 \pm 8.2$ & $35.5 \pm 8.6$ & 0.637 & 0.529 \\
\hline \multicolumn{5}{|l|}{ Complication } \\
\hline $\mathrm{Hb}(\mathrm{g} / \mathrm{L})$ & $86.7 \pm 12.1$ & $85.4 \pm 12.7$ & 0.295 & 0.770 \\
\hline $\mathrm{CO}_{2} \mathrm{CP}(\mathrm{mmol} / \mathrm{L})$ & $21.4 \pm 5.2$ & $20.5 \pm 6.2$ & 0.441 & 0.662 \\
\hline $\mathrm{K}^{+}(\mathrm{mmol} / \mathrm{L})$ & $4.33 \pm 0.54$ & $4.32 \pm 0.48$ & 0.055 & 0.956 \\
\hline $\mathrm{Ga}^{2+}(\mathrm{mmol} / \mathrm{L})$ & $1.94 \pm 0.31$ & $1.88 \pm 0.32$ & 0.537 & 0.595 \\
\hline $\mathrm{P}(\mathrm{mmol} / \mathrm{L})$ & $1.56 \pm 0.37$ & $1.61 \pm 0.75$ & 0.234 & 0.817 \\
\hline iPTH $(\mathrm{pg} / \mathrm{ml})$ & $92.5 \pm 15.8$ & $87.4 \pm 17.6$ & 0.858 & 0.398 \\
\hline Blood pressure control (mean arterial pressure (mmHg) & $96 \pm 13$ & $98 \pm 12$ & 0.453 & 0.654 \\
\hline BI & $85 \pm 11$ & $83 \pm 10$ & 0.539 & 0.594 \\
\hline HAMD & $7 \pm 3$ & $8 \pm 2$ & 1.122 & 0.271 \\
\hline
\end{tabular}

Ccr express the total rate of creatinine clearance in peritoneal dialysis patients, including residual renal creatinine clearance (Crcr) and peritoneal creatinine clearance (Cpcr). *Two groups were compared using Fisher's exact test. 
Table 2. Clinical effect comparison after 5 years of peritoneal dialysis

\begin{tabular}{|c|c|c|c|c|}
\hline Index & Agroup & B group & $t$ & $p$ \\
\hline Urine volume (ml/d) & $224 \pm 97$ & $255 \pm 110$ & 0.840 & 0.407 \\
\hline Ultrafiltration volume (ml/d) & $1436 \pm 226$ & $1446 \pm 342$ & 0.096 & 0.924 \\
\hline \multicolumn{5}{|l|}{ Adequacy of long-term peritoneal dialysis } \\
\hline $\mathrm{Kt} / \mathrm{V}$ (week) & $1.54 \pm 0.53$ & $1.56 \pm 0.74$ & 0.087 & 0.931 \\
\hline Cor $\left(\mathrm{L}\right.$ week ${ }^{-1} \quad\left(1.73 m^{2}\right)^{-1}$ & $54.23 \pm 10.12$ & $55.41 \pm 11.26$ & 0.310 & 0.759 \\
\hline \multicolumn{5}{|l|}{ Nutritional status } \\
\hline The incidence of malnutrition (SGA) & $73.3 \%$ & $35.3 \%$ & $*$ & 0.042 \\
\hline sALB (g/L) & $26.2 \pm 5.1$ & $34.4 \pm 3.8$ & 5.197 & 0.000 \\
\hline \multicolumn{5}{|l|}{ Complication } \\
\hline $\mathrm{Hb}(\mathrm{g} / \mathrm{L})$ & $83.4 \pm 13.3$ & $92.3 \pm 10.7$ & 2.096 & 0.045 \\
\hline $\mathrm{CO}_{2} \mathrm{CP}(\mathrm{mmol} / \mathrm{L})$ & $21.4 \pm 4.3$ & $23.1 \pm 3.4$ & 1.248 & 0.222 \\
\hline $\mathrm{K}^{+}(\mathrm{mmol} / \mathrm{L})$ & $4.54 \pm 0.71$ & $4.32 \pm 0.54$ & 0.993 & 0.328 \\
\hline $\mathrm{Ga}^{2+}(\mathrm{mmol} / \mathrm{L})$ & $1.88 \pm 0.37$ & $2.03 \pm 0.32$ & 1.230 & 0.228 \\
\hline $\mathrm{P}(\mathrm{mmol} / \mathrm{L})$ & $2.14 \pm 0.46$ & $1.76 \pm 0.55$ & 2.103 & 0.044 \\
\hline $\mathrm{iPTH}(\mathrm{pg} / \mathrm{ml})$ & $126.7 \pm 31.2$ & $102.3 \pm 17.6$ & 2.767 & 0.010 \\
\hline Blood pressure control (mean arterial pressure (mmHg) & $99 \pm 12$ & $90 \pm 11$ & 2.214 & 0.035 \\
\hline Rate of abdominal infection (times/month) & $0.092 \pm 0.014$ & $0.015 \pm 0.026$ & 10.224 & 0.000 \\
\hline Number of maintain dialysis & 7 & 15 & $*$ & 0.049 \\
\hline Dialysis duration (months) & $41.69 \pm 17.81$ & $59.00 \pm 4.00$ & 8.029 & 0.000 \\
\hline Employment rate (\%) & 0 & 29.4 & $*$ & 0.046 \\
\hline BI & $72 \pm 11$ & $86 \pm 8$ & 4.152 & 0.000 \\
\hline HAMD & $19 \pm 4$ & $7 \pm 4$ & 8.469 & 0.000 \\
\hline
\end{tabular}

*The two groups were compared using Fisher's exact test.

Table 3. Clinical effect comparison at the beginning of dialysis

\begin{tabular}{llllc}
\hline Index & Agroup & B group & $\boldsymbol{t}$ & $\boldsymbol{p}$ \\
\hline Urine volume (ml/d) & $962 \pm 428$ & $1106 \pm 281$ & 1.336 & 0.189 \\
Ultrafiltration volume (ml/d) & $1074 \pm 145$ & $647 \pm 2742$ & 0.763 & 0.450 \\
Adequacy of long-term peritoneal dialysis & & & & \\
Kt/V (week) & $1.41 \pm 0.22$ & $1.32 \pm 0.75$ & 0.563 & 0.577 \\
Nutritional status & & & & \\
$\quad$ The incidence of malnutrition (SGA) & $8.3 \%$ & $9.1 \%$ & $*$ & 1.000 \\
$\quad$ sALB (g/L) & $34.4 \pm 6.1$ & $35.4 \pm 8.1$ & 0.476 & 0.637 \\
Complication & & & & \\
$\quad \mathrm{Hb}(\mathrm{g} / \mathrm{L})$ & $85.5 \pm 12.4$ & $84.6 \pm 12.3$ & 0.247 & 0.806 \\
$\mathrm{CO}$ CP(mmol/L) & $21.5 \pm 5.3$ & $20.2 \pm 4.6$ & 0.885 & 0.381 \\
$\mathrm{~K}^{+}(\mathrm{mmol} / \mathrm{L})$ & $4.12 \pm 0.51$ & $4.32 \pm 0.33$ & 1.563 & 0.125 \\
$\mathrm{Ga} \mathrm{a}^{2+}(\mathrm{mmol} / \mathrm{L})$ & $1.89 \pm 0.42$ & $1.88 \pm 0.27$ & 0.095 & 0.925 \\
$\mathrm{P}(\mathrm{mmol} / \mathrm{L})$ & $1.54 \pm 0.25$ & $1.60 \pm 0.58$ & 0.462 & 0.646 \\
$\quad$ PTH (pg/ml) & $90.4 \pm 13.6$ & $87.3 \pm 14.3$ & 0.754 & 0.455 \\
$\mathrm{Blood}$ pressure control (mean arterial pressure (mmHg) & $95 \pm 11$ & $97 \pm 16$ & 0.498 & 0.621 \\
Employment rate (\%) & 29.2 & 27.3 & $*$ & 1.000 \\
$\mathrm{BI}$ & $85 \pm 9$ & $82 \pm 12$ & 0.964 & 0.340 \\
$\mathrm{HAMD}$ & $6 \pm 2$ & $7 \pm 3$ & 1.341 & 0.187 \\
\hline
\end{tabular}

*The two groups were compared using Fisher's exact test. 
When patients were treated continuously for 5 years (60 months), the above relevant data were compared (Table 4). There was no significant difference $(p>0.05)$ between groups with respect to residual urine volume, daily dialysis ultrafiltration, dialysis adequacy (Kt/V (weeks), Ccr), nutritional status (SGA, sALB), complications control as measured by the level of $\mathrm{Hb}, \mathrm{CO}_{2} \mathrm{CP}, \mathrm{K}^{+}, \mathrm{Ca}^{2+}$, P-, mean arterial blood pressure, abdominal infection rate, survival rate, or dialysis duration. Patients in group B had a higher iPTH, employment rate, and lower annual medical costs than group A. The difference was statistically significant $(p<0.05)$.

\section{Long term clinical effects comparison of patients undergoing DAPD at different dialysis doses}

Fifty-two patients who underwent peritoneal dialysis at our outpatient clinic or in our hospital for more than 5 years were selected to join in the study; they are divided into three groups (A, B, and C) according to the dose of daily dialysis. There were 17 patients in group A with a dialysis dose of $4 \mathrm{~L}, 19$ patients in group B with a dialysis dose of $6 \mathrm{~L}, 16$ patients in group $C$ with a dialysis dose of $8 \mathrm{~L}$, and the exchange time for every bag of dialysate was 4 hours. All of the patients were fasted during the night. There were no statistical differences between the groups in age, sex, weight, height, type of disease (percentage of nondiabetic) $(p>0.05)$ (data is not shown).

When patients were treated continuously for 3 months, the related index relevant data were compared (Table 5). The residual urine volume was statistically significant different between the 3 groups $(p<0.05)$ with a decreasing urine volume in the order $\mathrm{C}>\mathrm{B}>\mathrm{A}$. There was no significant difference $(p>0.05)$ between groups in dialysis adequacy (Kt/V (weeks), Ccr), nutritional status (SGA, sALB), complications control, blood pressure, BI, or HAMD.

Table 4. Clinical effect comparison after 5 years of dialysis

\begin{tabular}{|c|c|c|c|c|}
\hline Index & A group & B group & $t$ & $p$ \\
\hline Urine volume (ml/d) & $107 \pm 36$ & $125 \pm 42$ & 1.565 & 0.125 \\
\hline Ultrafiltration volume (ml/d) & $1655 \pm 163$ & $1574+245$ & 1.331 & 0.190 \\
\hline \multicolumn{5}{|l|}{ Adequacy of long-term peritoneal dialysis } \\
\hline Kt/V (week) & $1.32 \pm 0.35$ & $1.36 \pm 0.42$ & 0.352 & 0.727 \\
\hline \multicolumn{5}{|l|}{ Nutritional status } \\
\hline The incidence of malnutrition (SGA) & $16.7 \%$ & $22.7 \%$ & $*$ & 0.718 \\
\hline sALB (g/L) & $33.1 \pm 3.4$ & $31.5 \pm 4.7$ & 1.331 & 0.190 \\
\hline \multicolumn{5}{|l|}{ Complication } \\
\hline $\mathrm{Hb}(\mathrm{g} / \mathrm{L})$ & $90.2 \pm 11.2$ & $89.4 \pm 11.4$ & 0.240 & 0.811 \\
\hline $\mathrm{CO}_{2} \mathrm{CP}(\mathrm{mmol} / \mathrm{L})$ & $21.4 \pm 3.6$ & $20.3 \pm 2.4$ & 1.208 & 0.234 \\
\hline $\mathrm{K}^{+}(\mathrm{mmol} / \mathrm{L})$ & $4.62 \pm 0.22$ & $4.51 \pm 0.27$ & 1.520 & 0.136 \\
\hline $\mathrm{Ga}^{2+}(\mathrm{mmol} / \mathrm{L})$ & $1.78 \pm 0.36$ & $1.81 \pm 0.25$ & 0.325 & 0.746 \\
\hline $\mathrm{P}(\mathrm{mmol} / \mathrm{L})$ & $1.89 \pm 0.42$ & $1.73 \pm 0.31$ & 1.459 & 0.152 \\
\hline iPTH $(\mathrm{pg} / \mathrm{ml})$ & $123.8 \pm 12.4$ & $83.8 \pm 13.4$ & 10.516 & 0.000 \\
\hline Blood pressure control (mean arterial pressure (mmHg) & $97 \pm 11$ & $95 \pm 14$ & 0.541 & 0.591 \\
\hline Rate of abdominal infection (times/month) & $0.025 \pm 0.024$ & $0.028 \pm 0.017$ & 0.485 & 0.630 \\
\hline Number of maintain dialysis & 17 & 19 & $*$ & 0.289 \\
\hline Dialysis duration (months) & $56.82 \pm 6.13$ & $57.35 \pm 6.30$ & 0.289 & 0.774 \\
\hline Survival (\%) & 70.8 & 86.4 & $*$ & 0.289 \\
\hline Employment rate (\%) & 8.3 & 36.4 & $*$ & 0.032 \\
\hline BI & $71 \pm 14$ & $80 \pm 13$ & 2.253 & 0.029 \\
\hline HAMD & $19 \pm 2$ & $8 \pm 2$ & 18.634 & 0.000 \\
\hline Annual medical costs (million) & $13.47 \pm 2.38$ & $10.32 \pm 1.64$ & 5.180 & 0.000 \\
\hline
\end{tabular}

*The two groups were compared using Fisher's exact test. 
Table 5. Clinical effect comparison after 3 months of peritoneal dialysis

\begin{tabular}{|c|c|c|c|c|c|}
\hline Index & Agroup & B group & C group & $f$ & $p$ \\
\hline Urine volume (ml/d) & $1046 \pm 414$ & $745 \pm 332^{*}$ & $578 \pm 256^{* \#}$ & 8.030 & 0.001 \\
\hline Ultrafiltration volume (ml/d) & $324 \pm 265$ & $463 \pm 221^{*}$ & $626 \pm 294^{* \#}$ & 5.587 & 0.007 \\
\hline \multicolumn{6}{|l|}{ Adequacy of long-term peritoneal dialysis } \\
\hline $\mathrm{Kt} / \mathrm{V}$ (week) & $1.14 \pm 0.62$ & $1.67 \pm 0.86$ & $1.32 \pm 0.75$ & 2.310 & 0.110 \\
\hline Cor $\left(\mathrm{L}\right.$ week $\left.{ }^{-1} \quad\left(1.73 m^{2}\right)^{-1}\right)$ & $51.54 \pm 14.17$ & $59.06 \pm 11.61$ & $56.23 \pm 10.44$ & 1.728 & 0.188 \\
\hline \multicolumn{6}{|l|}{ Nutritional status } \\
\hline The incidence of malnutrition (SGA) & $11.80 \%$ & $15.80 \%$ & $37.50 \%$ & 3.790 & 0.150 \\
\hline sALB (g/L) & $37.4 \pm 8.2$ & $35.7 \pm 7.9$ & $32.5 \pm 7.3$ & 1.662 & 0.200 \\
\hline \multicolumn{6}{|l|}{ Complication } \\
\hline $\mathrm{Hb}(\mathrm{g} / \mathrm{L})$ & $91.7 \pm 14.1$ & $99.4 \pm 12.3$ & $89.3 \pm 16.4$ & 2.452 & 0.097 \\
\hline $\mathrm{CO}_{2} \mathrm{CP}(\mathrm{mmol} / \mathrm{L})$ & $21.4 \pm 5.2$ & $23.1 \pm 4.7$ & $23.7 \pm 3.5$ & 1.153 & 0.324 \\
\hline $\mathrm{K}^{+}(\mathrm{mmol} / \mathrm{L})$ & $4.33 \pm 0.54$ & $4.37 \pm 0.56$ & $4.04 \pm 0.72$ & 1.472 & 0.239 \\
\hline $\mathrm{Ga}^{2+}(\mathrm{mmol} / \mathrm{L})$ & $1.94 \pm 0.31$ & $2.04 \pm 0.32$ & $2.01 \pm 0.25$ & 0.528 & 0.593 \\
\hline $\mathrm{P}(\mathrm{mmol} / \mathrm{L})$ & $1.42 \pm 0.44$ & $1.56 \pm 0.61$ & $1.64 \pm 0.86$ & 0.484 & 0.620 \\
\hline iPTH (pg/ml) & $92.5 \pm 15.8$ & $89.4 \pm 22.1$ & $81.6 \pm 16.7$ & 1.497 & 0.234 \\
\hline Blood pressure control (mean arterial pressure (mmHg) & $90 \pm 13$ & $94 \pm 17$ & $98 \pm 12$ & 1.284 & 0.286 \\
\hline $\mathrm{BI}$ & $91 \pm 12$ & $86 \pm 8$ & $83 \pm 10$ & 2.683 & 0.078 \\
\hline HAMD & $6 \pm 3$ & $7 \pm 4$ & $9 \pm 5$ & 2.328 & 0.108 \\
\hline
\end{tabular}

*Comparison with A group $p<0.05$, ${ }^{*}$ Comparison with A group $p<0.05$, Ccr total rate of creatinine clearance in peritoneal dialysis patients, including residual renal creatinine clearance (Crcr), and peritoneal creatinine clearance (Cpcr).

When the patients were continuously treated for 5 years (60 months), the relevant index data described above were compared (Table 6). All of patients had a good quality of life. The residual urine volume remains statistically different between the 3 groups $(p<0.05)$ with a decreasing volume in the order $\mathrm{C}>\mathrm{B}>\mathrm{A}$. The dialysis adequacy was much lower in group A patients $(p<0.05)$. There was no significant different between groups B and C $(p>0.05)$. There is no significant difference in nutritional status between patients in groups A and B ( $p>0.05)$, but their status was much better than that of patients in group $\mathrm{C}(p<0.05)$. There was no significant difference in abdominal infection rate between patients in groups A and B ( $p>0.05)$, but the rate was much higher than that of group $C$ patients $(p<0.05)$. There were no significant differences in the complications control, blood pressure, and BI between the groups ( $p>0.05$ ). The HAMD score for patients in group $\mathrm{C}$ was higher than that of patients in groups A and B $(p<0.05)$.

\section{Discussion}

Only $10 \%$ of the total number of dialysis patients underwent PD treatment. Limitations, side effects, and economic factors were the main rational for the long-term application.
The patients subjected to long-term DAPA were able to obtain satisfactory clinical therapeutic efficacy. They could maintain nutritional status, control complications, regulate blood pressure, and had a reduced infection rate and other aspects in comparison with HD or CAPA patients. The treatment was advantageous in reducing degree of depression in dialysis patients, ensuring better life quality, alleviating economic burden, and other aspects. The dose of dialysis needs to be adjusted for different individuals to achieve satisfactory clinical effects.

Through long-term observation, DAPD with an individualized dialysis dose mode is better than other modes of treatment. A dry peritoneal cavity at night protected abdominal peritoneal mesothelial cells by the dialysate. The cells are self-repairing. DAPD can delay the peritoneal failure, improve the abdominal internal organ function, reduce fluid retention, and the adverse effects on the patient's gastrointestinal tract. Thus, DAPD increases the patients' appetite, digestion, and absorption capacity. The DAPD patients have a good nutritional status and quality of life. Stability of the cardiovascular system improves the patient's nutritional status and resistance [4], reduces medical costs, and the economic pressure incurred by the treatment. Therefore, patients are more willing 
Table 6. Clinical effect comparison after 3 months of peritoneal dialysis

\begin{tabular}{|c|c|c|c|c|c|}
\hline Index & Agroup & B group & C group & $f$ & $p$ \\
\hline Urine volume (ml/d) & $977 \pm 434$ & $659 \pm 372^{*}$ & $516 \pm 224^{* *}$ & 7.280 & 0.002 \\
\hline Ultrafiltration volume (ml/d) & $436 \pm 248$ & $642 \pm 383^{*}$ & $855 \pm 331^{* *}$ & 6.730 & 0.003 \\
\hline \multicolumn{6}{|l|}{ Adequacy of long-term peritoneal dialysis } \\
\hline Kt/V (week) & $1.04 \pm 0.57$ & $1.67 \pm 0.64^{*}$ & $1.56 \pm 0.74^{*}$ & 4.657 & 0.014 \\
\hline Cor $\left(\mathrm{L} \quad\right.$ week $^{-1} \quad\left(1.73 m^{2}\right)^{-1}$ & $44.23 \pm 14.38$ & $57.62 \pm 12.34^{*}$ & $55.41 \pm 11.26^{*}$ & 5.534 & 0.007 \\
\hline \multicolumn{6}{|l|}{ Nutritional status } \\
\hline The incidence of malnutrition (SGA) & $17.60 \%$ & $21.10 \%$ & $56.3 \%{ }^{* \#}$ & 7.093 & 0.029 \\
\hline sALB (g/L) & $36.2 \pm 7.8$ & $36.6 \pm 4.3$ & $26.4 \pm 4.8^{* *}$ & 16.487 & $<0.001$ \\
\hline \multicolumn{6}{|l|}{ Complication } \\
\hline $\mathrm{Hb}(\mathrm{g} / \mathrm{L})$ & $90.4 \pm 13.3$ & $96.6 \pm 11.5$ & $87.3 \pm 13.7$ & 2.426 & 0.099 \\
\hline $\mathrm{CO}_{2} \mathrm{CP}(\mathrm{mmol} / \mathrm{L})$ & $22.5 \pm 4.6$ & $24.5 \pm 3.2$ & $23.1 \pm 3.4$ & 1.343 & 0.270 \\
\hline $\mathrm{K}^{+}(\mathrm{mmol} / \mathrm{L})$ & $4.57 \pm 0.74$ & $4.61 \pm 0.47$ & $4.22 \pm 0.56$ & 2.163 & 0.126 \\
\hline $\mathrm{Ga}^{2+}(\mathrm{mmol} / \mathrm{L})$ & $1.88 \pm 0.37$ & $2.15 \pm 0.46$ & $2.03 \pm 0.37$ & 1.992 & 0.147 \\
\hline $\mathrm{P}(\mathrm{mmol} / \mathrm{L})$ & $2.04 \pm 0.46$ & $1.81 \pm 0.33$ & $1.77 \pm 0.57$ & 1.724 & 0.189 \\
\hline iPTH (pg/ml) & $116.7 \pm 31.6$ & $99.1 \pm 17.6$ & $102.5 \pm 19.4$ & 2.565 & 0.087 \\
\hline Blood pressure control (mean arterial pressure (mmHg) & $91 \pm 11$ & $93 \pm 12$ & $96 \pm 14$ & 0.683 & 0.510 \\
\hline Rate of abdominal infection (times/month) & $0.032 \pm 0.008$ & $0.037 \pm 0.023$ & $0.093 \pm 0.035$ & 32.151 & $<0.001$ \\
\hline BI & $88 \pm 10$ & $84 \pm 9$ & $82 \pm 8$ & 1.897 & 0.161 \\
\hline HAMD & $7 \pm 3$ & $10 \pm 4^{*}$ & $13 \pm 4^{* \#}$ & 10.822 & $<0.001$ \\
\hline
\end{tabular}

${ }^{*}$ Comparison with A group $p<0.05,{ }^{\sharp}$ Comparison with A group $p<0.05$

to accept the dialysis method and patient compliance improves. Many studies suggest that anxiety and depression are common in uremic patients [5-7]. DAPD with an individualized dialysis dose mode can alleviate depression and economic pressure. DAPD can also reduce the psychological and mental stress caused by end-stage renal failure.

Using this model, most PD patients have been on treatment for more than 10 years, and this therapy is still continued. The majority of patients with more than 5 years treatment have maintained a satisfactory clinical outcome. We recommend that peritoneal dialysis as the first choice in the developing regions and countries where the medical level is inequitable, medical conditions are limited, the development of dialysis is not universal.

The authors have no conflict of interest to report.

\section{References}

1. Eknoyan G, Beck GJ, Cheung AK, Daugirdas JT, Greene T, Kusek JW, et al. Effect of dialysis dose and membrane flux in maintenance hemodialysis. New Engl J Med. 2002; 347:2010.
2. Klassen PS, Lowrie EG, Reddan DN, DeLong ER, Coladonato JA, Szczech LA, et al. Association between pulse pressure and mortality in patients undergoing maintenance hemodialysis. JAMA. 2002; 288:1548-55.

3. Singri N, Johnstone D, Paparello J, Khosla N, Ahya SN, Ghossein C, et al. Effect of predialysis eating on measurement of urea reduction ratio and $\mathrm{Kt} / \mathrm{V}$. Adv Chronic Kidney Dis. 2004; 11:398.

4. Kutner NG, Zhang R, McClellan WM. Patient-reported quality of life early in dialysis treatments: the effects associated with usual exercise activity. Nephro Nurs J. 2000; 27:357-67.

5. Lye WC, Chan PS, Leong SO, van der Straaten JC. Psychosocial and psychiatric morbidity in patients on CAPD. Adv Perit Dial. 1997; 13:134-6.

6. Juergensen PH, Zemchenkov A, Watnick S, Finkelstein S, Wuerth D, Finkelstein FO. Comparison of qualityof-life assessment in Russia and the United States in chronic peritoneal dialysis patients. Adv Pert Dial. 2002; 18:55-7.

7. Hinrichsen GA, Lieberman JA, Pollack S, Steinberg H. Depression in hemodialysis patients. Psychosomatics. 1989; 30:284-9. 